\title{
In Quest of a Wittgensteinian Hinge Epistemology
}

Annalisa Coliva

Department of Philosophy, UC Irvine

\section{Introduction}

Hinge epistemology is a family of theories about justification (and knowledge) which give centre-stage to Wittgenstein's notion of a "hinge". In the following, I will first put forward some basic methodological considerations regarding the relationship between merely exegetical work on, in particular, Wittgenstein's texts, and more theoretically committed work, which aims at developing suggestions that can be found in the texts, even though they are not clearly attributable as such to their author $(\$ 1)$. I will then summarize the main tenets of what, to date, is still the most widespread reading of On Certainty $(\$ 2)$ - the so-called "framework reading". In light of the initial methodological considerations and of this exegesis of On Certainty, I will then review some contemporary attempts at developing Wittgenstein's ideas in an anti-skeptical direction, such as Crispin Wright's, Michael Williams' and Duncan Pritchard's (\$3). I will argue that, their intrinsic merits notwithstanding, they fail to take proper measure of Wittgenstein's own position. I will then close by sketching my own version of hinge epistemology and by highlighting points of contact and disagreement with Wittgenstein's own views as portrayed by the framework reading ( $\$ 4)$.

\section{Some basic methodological considerations}

Let me start with some platitudes. When engaged in doing history of philosophy - analytic or otherwise - as opposed to doing philosophy as such, we are first and foremost involved in a process of interpretation of more or less remote texts. Such interpretations cannot be assessed based merely on their own specific philosophical interest and merits, if they are meant as exegeses. Rather, they will have to be evaluated with respect to the text(s) of which they are purported interpretations, as well as to other historical evidence pertaining to what we may generically call the "context" in which the work was created. ${ }^{1}$ I believe there is a

\footnotetext{
${ }^{1}$ For instance, On Certainty cannot be read without reference to G. E. Moore's epistemological papers, especially “A defence of common sense" (1925) and "Proof of an external world" (1939). It will also be important to consider that Wittgenstein got interested in it through discussions with Norman Malcolm, who, at the time, was writing on the topic and was criticizing Moore for his use of "I know" in connection with his truisms and premises of his proof. In effect, however, Malcolm was applying to those propositions considerations about the use of "I know" that Wittgenstein himself had developed in the 1930's in connection with psychological avowals. I discuss this issue at length in Coliva 2010, chapter 2. In addition, the influence on Wittgenstein of Cardinal Newman's An Essay in Aid of the Grammar of Assent should be taken into proper consideration. On the latter topic, see
} Kienzler (2006) and Pritchard (2019). 
strong tendency, especially in analytic philosophy, to forget such a basic methodological requirement and thus to end up presenting more how a text struck one, as it were, than what that text itself tried to say, in light of its author's intentions and context. However, to put it baldly, rational reconstructions without textual and contextual evidence, or else supported by very little textual and contextual evidence, seem to me to be "empty" - to use a piece of Kantian terminology. That is to say, they are devoid of historical content and therefore interest, as exegeses.

As an analytic philosopher, however, I am sensitive to what I think are, upon close examination, just rational reconstructions. Take for instance Saul Kripke’s work on Wittgenstein's remarks on rule following and the so-called "private language argument". Its exegetical accuracy is extremely debatable - indeed, as a historian of analytic philosophy, I would rank myself among those who think that "Kripkenstein" is clearly not Wittgenstein. Yet, there is no denying that that reading is intellectually engaging and philosophically fruitful. This creates a tension between, as it were, rational reconstructions that are historically empty and historical reconstructions that might end up being philosophically "blind" - to pursue our Kantian comparison - by being exegetically accurate but not philosophically very illuminating or fruitful.

How can one then resolve the pressure between, on the one hand, offering interpretations that may be accurate from a textual point of view, yet not philosophically germane to future investigation and, on the other hand, presenting rational reconstructions that may end up having little to do with the text they aim to be exegeses of, while spurring - in the best case scenario - a lot of philosophical interest?

I think the tension can be resolved by being very explicit about the nature of the claims one is putting forward. If they are exegetical ones, textual and contextual evidence should be provided. If, in contrast, they are possible developments of ideas that have occurred to one while reading the text, they should be advertised as such. There is a strong tendency, especially when Wittgenstein's texts are concerned, to be inexplicit about the nature of the claims one is advancing. Here I will not try to venture an explanation of such an attitude. I think, however, that being explicit about the nature of the claims one is putting forward will have the methodological advantage of determining the criteria to be used in order to evaluate them. If one's claims are exegetical in nature, they will have to be evaluated based on textual and contextual evidence in their support. If, in contrast, they are meant as personal developments of ideas, which can be found more or less vaguely expressed in the text, they will have to be assessed on philosophical merit. Furthermore, along this dimension, there will be more or less $X$-ian, i.e. Wittgensteinian, Kantian, Aristotelian, etc., philosophical proposals, depending on how close they are to the texts by which they have been inspired. In the second half of this paper, I will evaluate three specimens of hinge epistemology along this dimension, leaving for other occasions their assessment on purely philosophical merit. 


\section{The framework reading of On Certainty}

What, to date, remains the most widespread reading of On Certainty is the so-called "framework reading". 2 This, however, is not a unified view, but a family of interpretations, which fluctuate along various dimensions. Yet, central to all of them is the idea that "hinges" play a peculiar, rule-like role (OC 95) which ultimately makes them immune to sceptical assaults while also divesting them of the status of knowledge. Accordingly, propositions like "Here's my hand" (in Moore-like situations), "Nobody has ever been on the Moon" (around 1949), "The Earth has existed for a very long time", "My name is AC", "There are physical objects", are rules of "evidential significance" (Wright 1985), or "norms of description" (OC 167, 321). For instance, they have to stay put for us to be in a position to take perceptual evidence to bear on the truth of specific propositions about material objects; or for us to be able to take geological evidence to bear on the determination of the precise age of our planet or of a fossil that we have found on it; or to take our personal memories to bear on the truth of propositions regarding our own past, etc. Since justification and knowledge, to the extent that knowledge involves justification, depend on holding them fast, hinges, for Wittgenstein, are neither justified nor unjustified, neither known nor unknown (OC 91, 110, 137, 151, 466, 559, 613-614). In other words, justification and knowledge, as well as doubt, are possible only within the limits set by taking hinges for granted. It is worth stressing that even though, for Wittgenstein, the origin of hinges lies in our shared practices, hinges do play a regulative and normative role in guiding us in the practice of acquiring and assessing evidence for or against ordinary (mostly) empirical propositions, thus rendering the latter justified, or unjustified, known or doubtful. Thus, as we might put it, they are constitutive elements of epistemic rationality.

Furthermore, hinges are not bipolar - that is, liable to truth and falsity (OC 94, 197, 199, 200, 205) - for Wittgenstein. At most, they may be taken to be "unipolar" (OC 206, 514-515), insofar as truth may be predicated of them only in a minimalist or deflationary sense. Yet, they are propositions (OC 95-99, 309, 318-21 cf. PI 65). ${ }^{3}$ In particular, while playing a rule-like role, they retain some descriptive content for they constitute a Weltbild, i.e. a world-picture (OC 93-95, 233, 262). Just as those pictures that sometimes guide us in performing certain activities, like assembling a chest of drawers, so they guide us in our treatment of any kind of evidence, let it be perceptual, memory-based, geological, etc.

\footnotetext{
2 See, for instance, Wright 1985, McGinn 1989, Stroll 1994, Moyal-Sharrock 2005, Coliva 2010, Schönbaumsfeld 2017.

3 This point has been vigorously denied by Moyal-Sharrock 2005, but it is fair to say that her extreme view, according to which hinges are not propositions, since they aren't bipolar, has not been met by consensus, not even among supporters of a framework reading of On Certainty.
} 
While they do not normally bear saying, since their function is not descriptive, but prescriptive and enabling with respect to our epistemic practices, we sometimes use hinges in perfectly legitimate language games, like teaching children about them, or reminding deluded subjects, or philosophers, of their role (OC $106,165,233,281,350,355,374,406-423,450,467,674)$.

Concerning philosophical scepticism, On Certainty presents a two-pronged strategy. On the one hand, sceptical doubts are said to flout the conditions that govern ordinary ones. In particular, they are not sustained by reasons (OC 231, 342, 452-4, 458) as there cannot be reasons to doubt those hinges that allow us to acquire reasons for or against ordinary empirical propositions in the first place. Thus, sceptical doubts are not rational, since they are unsupported by reasons (OC 56,151, 318, 342). On the other hand, since only ordinary doubts that are supported by reasons are meaningful, for Wittgenstein, sceptical doubts are not meaningful either (OC 347-55, 383, 676). It may seem otherwise, at first glance, but only because we project sense onto the words used to express them from other contexts of their use in which those very words do have a meaning. ${ }^{4}$

Finally, the title given to Wittgenstein's collection of notes by the curators - i.e. On Certainty - is entirely appropriate. For hinges are certain in a grammatical (or "logical") sense as opposed to a psychological (or subjective) one (OC 21, 26, 43, 51, 53, 57-60, 82, 98, 110, 136, 155, 194, 308, 319, 358-361, 375, 447, 454, $501,618,628$ ), due to their role of basic rules of our (linguistic and) epistemic practices. Furthermore, our attitude with respect to them is one of acceptance (or trust), which shows no doubt and displays itself mostly in action: we behave in accord with them, accept reproach for not doing so and pass them on to children (OC 150, 275, 337, 344, 360, 509, 599-600, 603, 672).

\section{Hinge epistemologies: Wright, Williams and Pritchard}

\subsection{Wright and Williams}

Crispin Wright has repeatedly advertised his version of hinge epistemology - as I would call it - as Wittgensteinian. Central to it, it is the idea that there are entitlements - i.e. non-evidential warrants - for basic, general presuppositions, such as "There is an external world", "My sense organs work mostly reliably", "I am not the victim of a lucid and sustained dream", etc.

\footnotetext{
${ }^{4}$ See Conant 1998.
} 
Michael Williams too, in recent years, has proposed an epistemic reading of On Certainty..$^{5}$ Accordingly, we may have entitlements, i.e. non-evidential justifications, and perhaps even knowledge, of contextually determined hinges, which could be regarded as minimally truth-apt propositions. As he writes:

Holding some particular propositions fast need not be a matter of credulity: to hold them fast is reasonable. So while they are (in one sense) ungrounded, we are justified in cleaving to them. In this way, they can be the objects of beliefs that are true (in a deflationary sense of 'true') and justified (though not derived from evidence). Thinking of 'justified true belief' in this second way, even basic certainties can amount to knowledge" (2004, p. 280).

With respect to their favourite hinges, both Wright and Williams would concur that sceptical doubts would be unmotivated and based on the mistaken idea that all justification (and knowledge) should be evidential in nature and, in particular, based on sensory experience. Hence, (at least part of) the sceptic's mistake would depend on too narrow a notion of justification.

Before dwelling further on Williams' proposal, let us ask how Wittgensteinian would this kind of hinge epistemology be. No doubt, it is easy to imagine for instance a Crispin Wright who might want to protest that even if entitlements are not Wittgenstein's creatures, they are in his spirit. It is equally easy to imagine a Michael Williams who, besides defending the idea of entitlements in this way, may actually say that an externalist conception of knowledge is in keeping with Wittgenstein's own pronouncements in On Certainty. ${ }^{6}$

In response to such a kind of defense, I would only stress that nothing seems to me firmer than a negation like the one we find in a passage, which, ironically, is often appealed to by supporters of the epistemic reading, which is worth citing in full and in its proper context:

The questions that we raise and our doubts depend on the fact that some propositions are exempt from doubt, are, as it were hinges [die Angeln] on which those turn. (OC 341)

\footnotetext{
${ }^{5}$ Williams, in conversation, has resisted being considered a hinge epistemologist, for reasons that largely evade me. In fact, to my knowledge, he has been one of the first epistemologists who have developed a Wittgenstein-inspired theory of knowledge, with a characteristic contextualist flavor to it. The fact that it differs from other ones is unimportant, once hinge epistemology is considered a family of views that give center-stage to Wittgenstein's hinges and to their peculiar role in the structure of justification and knowledge. Another contemporary supporter of an epistemic reading of On Certainty is Kusch 2016.
}

${ }^{6}$ An earlier supporter of such a reading of Wittgenstein is Morawetz 1978. 
That is to say, it belongs to the logic (my emphasis) of our scientific investigations that certain things are in deed [in der Tat] not doubted. (OC342)

But it isn't (my emphasis) that the situation is like this: we just can't investigate everything, and for that reason we are forced to rest content with assumption. If I want the door to turn, the hinges must (my emphasis) stay put. (OC 343)

Here Wittgenstein is introducing the idea of hinges and is making clear that it belongs to the logic - i.e. to the norms that regulate our investigations - that certain propositions are in fact not doubted. This, however, isn't due to the fact that since we cannot - pragmatically - investigate everything, if we ever want to start investigate anything, we have to content ourselves with assumptions, as Wittgenstein explicitly acknowledges in OC 343.

By contrast, on Wright's view, it is precisely the fact that certain cognitive projects are valuable or even indispensable to us that forces us, in order to get them started and to pursue them, to rest content with their characteristic assumptions. Here is a telling passage:

If a cognitive project is indispensable, or anyway sufficiently valuable to us (..) and if the attempt to vindicate (some of) its presuppositions would raise presuppositions of its own of no more secure an antecedent status, and so on ad infinitum, then we are entitled to (...) the original presuppositions without specific evidence in their favour. (2004, p. 192)

Yet, for Wittgenstein, saying that it belongs to the logic of our investigations that certain propositions aren't doubted simply means that it is a constitutive element of our empirical inquiries that, whenever evidence is collected for or against any empirical proposition, certain other propositions have to be kept fixed. Hence, it is constitutive of empirical inquiries, and not just a fact about our nature or pertaining to pragmatics, that certain propositions are taken for granted.

However, saying this does nothing to corroborate the idea that hinges are therefore reasonable and reasonable because they would be somewhat epistemically justified, albeit non-evidentially, as they would be required in order to collect evidence for or against ordinary empirical propositions. Indeed Wittgenstein repeatedly points out that they are neither reasonable nor unreasonable. Yet he does say that they are required in order to collect evidence for or against ordinary empirical propositions. What that means, I take it, is that they are rationally mandated. Yet a rational mandate is not a sui generis kind of justification. It is a requirement for reasons and reasoning to be possible in the first place, not a product of reason, which, like any proper 
epistemic good, makes certain propositions somehow justified and therefore reasonable. Hence, hinges must stay put, and thus behave like rules, for us to be in a position to acquire evidence that may add up to justification and sometimes to knowledge, or that can motivate rational doubts and eventually the dismissal of a previously held belief. Thus, I think there is nothing in the key passages usually appealed to by supporters of entitlements to corroborate their view.

Nor is there anything which suggests that knowledge, for Wittgenstein, is to be understood somewhat in an externalist spirit and that it can be attained even if one is in no position to produce reasons for one's own true beliefs. In fact, the idea that Wittgenstein would allow for the possibility of knowledge even when no reasons can be produced in favor of one's claim is based on disregarding the distinction between empirical (ordinary) and grammatical uses of "I know" he draws in On Certainty. As Wittgenstein clearly writes in OC 58-59:

If "I know etc" is conceived as a grammatical proposition, of course the "I" cannot be important. And it properly means “There is no such thing as a doubt in this case” or "The expression 'I do not know' makes no sense in this case". And of course it follows from this that "I know" makes no sense either.

"I know" is here a logical insight. Only realism can't be proved by means of it.

It should be kept in mind that, for Wittgenstein, only grammatical uses of "I know" are not backed by reasons. Furthermore, and as weird as that may be, they actually don't express, for him, an epistemic relation between a subject and a proposition. Rather, they express a kind of certainty, which would be more perspicuously expressed by saying "Here a doubt is (logically) impossible". Thus, we do not have anything in On Certainty resembling the externalist idea that, even if we cannot produce reasons in favor of knowledge claims regarding hinges, we would know them nonetheless. Rather, we have the suggestion that the use of "I know" in their connection is a misleading expression of the kind of certainty, which characterizes them. Namely, a certainty that has nothing subjective or psychological about it, but which depends on the role hinges play in the relevant epistemic practices.

That is, all we get from these and other key passages in On Certainty is the idea that justification and knowledge do not take place in a vacuum. They always depend on there being certain hinges, which, as such, cannot themselves be justified or known, yet allow us to acquire evidence for or against ordinary empirical propositions. They are therefore constitutive of the practice that in turn determines what being epistemically rational amounts to. Some of them can change in time - "Nobody has ever been on the Moon" is no longer 
a hinge for us - and according to context - sometimes "Here is my hand" is an empirical proposition we subject to verification and control. Yet, there are several of them we simply cannot revise, e.g. "The Earth has existed for a very long time", "There are physical objects", etc. on pain of giving up all our system of beliefs. This is not to say that they are metaphysically necessary but only that they play such a fundamental role in our Weltbild that, from within it - as we in fact are - we can't actually find any reason to doubt them.

At this stage, one may ask whether entitlements are any good, as such. In response, it is worth pointing out that Wright's entitlements are said to be epistemic warrants, yet they are also said not to speak to the likely truth of the propositions they warrant. This gives them a strange status, which runs the risk of conflating pragmatic and epistemic warrants. He writes:

The unified strategy (...) concedes the basic point of the sceptical arguments to which it reacts, namely that we indeed have no claim to know, in any sense involving possession of evidence for their likely truth, that certain cornerstones of what we take to be procedures yielding knowledge and justified belief hold good (2004, p. 206).

Pragmatic warrants are such that they do not speak to the truth of the proposition they warrant. They merely give us practical reasons to believe/endorse/act based on a given proposition. So, even if the kind of project involved is one of complying with epistemic rationality, pointing out that, to that end, we should trust in certain assumptions, does not make those assumptions more likely true than not. Yet, it may be a perfectly good reason - from a practical point of view - to go on as if they were true.

In Wright (2014, p. 214) entitlements are introduced as "warrant(s) to accept a proposition as true". Yet no argument is given to that effect, save one concerned with the kind of attitude involved. Namely, an attitude of trust, which entails trusting in the truth of what is being relied upon. This obviously is no argument for the truth of the proposition trusted on, though. For it merely makes explicit the meaning of "trust"; or, if you will, it makes explicit the norm of trust. That is, what makes trust correct, when complied with, or incorrect otherwise. Yet, this is not a good response to the challenge of providing epistemic warrants - albeit non-evidential ones - for the relevant hinges. For epistemic warrants are such that the proposition thereby warranted is, as such, more likely to be true than not. Merely noticing that we trust hinges and thus accept them as true, does not make their actual truth any more likely, though. Thus, the take home message is that entitlements are not genuinely epistemic warrants; for they do not speak to the likely truth of the proposition they are supposed to warrant. 
Let us take stock. I have argued that Wright's and Williams' readings of On Certainty do not find adequate support in the text. I have also raised some doubts about the soundness of the notion of entitlement as proposed by Wright. ${ }^{7}$ To the extent that Williams' entitlements resemble Wright's - something on which there is no clear textual evidence as far as I can tell - the worries raised against the latter apply to the former. If, in contrast, as one may surmise, Williams' entitlements are in the vein of Burge's externalist notion of justification, and, together with a deflationary conception of truth, were used to bolster the idea that hinges are known - albeit in an externalist sense - we have seen how remote and at odds with Wittgenstein's own writings that proposal is.

\subsection{Pritchard}

Let us now turn to Pritchard's (2016) recent rational reconstruction of On Certainty, which is at the service of a "bioscopic" strategy against radical skepticism. Pritchard is explicit that his aim is not so much to engage in exegesis, but rather to develop Wittgensteinian ideas in a more systematic way. Thus, he is not guilty, by my lights, of attributing to Wittgenstein his own epistemological views. Still, one may raise the issue of how Wittgensteinian Pritchard's position is, and of how successful it is. I will not address the latter question directly here. ${ }^{8}$ Yet, he following remarks that speak more to the former issue will also cast some doubts about the prospects of success of Pritchard's approach, in my opinion.

There are three key elements to Pritchard's strategy. First, his idea that we have "hinge commitments", as he calls them, and that acknowledging their proper role will help one resist Closure-based arguments for radical skepticism. Second, that there is nothing in On Certainty that speaks to Underdetermination-based skeptical arguments. Third, that this, in its turn, motivates supplementing Wittgenstein's own insights in $O n$ Certainty with epistemological disjunctivism. Hence, first appearances notwithstanding, hinge epistemology and disjunctivism are mutually supportive. For, on the one hand, the former shows the locality of epistemic evaluation and therefore sets the boundaries within which the factive rational support for our beliefs disjunctivists hold we have can in fact obtain. On the other hand, disjunctivism supplements hinge epistemology by providing it with the means to deal with Underdetermination-based skepticism.

A hinge commitment, for Pritchard, who refuses the non-propositional reading of hinges and does not consider them as rules but as propositions, is a peculiar kind of attitude, different from belief, or acceptance, which is a-rational and has visceral and animal elements to it. It is helpful, in connection with Closure-based

\footnotetext{
${ }^{7}$ For further criticism, see Coliva 2019a.

${ }^{8}$ For a fuller discussion of Pritchard 2016, see Coliva 2016 and 2019b.
} 
arguments for skepticism, ${ }^{9}$ according to Pritchard, because it shows how Closure is not applicable when hinges are concerned. For, hinges are not the object of belief, belief is necessary for knowledge, and Closurebased arguments for skepticism concern the possibility of extending knowledge from known premises to the conclusion of valid arguments through known entailments. In particular, according to Pritchard, we do not acquire a belief in, let alone knowledge of, a hinge, like "there is an external world" or "I am not a BIV", by reasoning from "Here is a tree", "If there is a tree here, I'm not a BIV/there is an external world", to "I'm not a BIV/there is an external world". Thus, Closure cannot be applied to entailments figuring hinges as consequents and cannot be used, by contraposition, to claim that since we do not have knowledge of the conclusion of the previous inference, we do not have knowledge of its premises either, and, in particular, of ordinary empirical propositions such as "Here is a tree".

In other writings, ${ }^{10} \mathrm{I}$ have raised some doubts about this strategy, which seems to me to conflate Closure with Transmission-failure, and which does not seem to me to be able to save the unconditional validity of Closure, contrary to Pritchard's aim. Indeed, it can be re-described as showing that Closure holds only restrictedly. That is, for the subset of all propositions, including hinges, which contains ordinary empirical propositions only. In fact, the non-applicability of Closure to hinges would follow more naturally if one denied, like Moyal-Sharrock's Wittgenstein, that hinges are propositions, or if one denied they are so in the sense of the term usually assumed by supporters of Closure, which is such to exclude the possibility for propositions believed or known to be rules.

What is also striking, from a Wittgensteinian perspective, is Pritchard's insistence on the visceral elements of our attitude towards hinges together with the denial that it is a kind of acceptance or trust, as Wittgenstein repeatedly calls it in $O n$ Certainty, that mostly displays itself in action (see $\$ 2$ ). As a result, the notion of commitment, in relation to hinges, Pritchard places so much emphasis on seems to veer towards elusiveness, in a way in which, I think, Wittgenstein's own remarks, while certainly open to interpretation, do not.

Turning to Underdetermination-based skepticism, the issue is this. If you hold that it is possible for a subject to have the same kind of evidence irrespective of whether she is actually perceiving a tree in front of her, or whether she is merely hallucinating one, it follows that, whatever is rationally available to a subject actually falls short of providing her with knowledge of (or justified belief that) "Here is a tree". According to Pritchard, Wittgenstein says nothing that could speak to this worry - whence the need to supplement his

\footnotetext{
${ }^{9}$ Closure-based arguments for skepticism have the following form: you don't know that $p$ (where $p$ is a ordinary empirical proposition) unless you know you are not a BIV (or that there is an external world). Since you cannot know the latter, you don't know that $p$ either.

${ }^{10}$ See, in particular, Coliva 2019b.
} 
position with disjunctivism, which allows us to have factive reasons for perception-based beliefs about physical objects in our surroundings. For, when you see a tree in front of you, you take in that very fact, while, when you are hallucinating one, you merely have an experience or an appearance as of a tree.

I have to confess that here too I think that the strategy seems to be based on failing to appreciate key elements of On Certainty. For Wittgenstein's own insistence on the locality of reasons is matched by the idea that knowledge and justification do take place. Yet, they are not direct or immediate, since they take place within a system of hinges. The latter are not themselves known or justified, yet stand fast for all of us and actually allow us to form justified beliefs and to gain knowledge of (among others) ordinary empirical propositions about physical objects in our surroundings. That is, by means of hinges such as "There is an external world" and "I'm not a BIV", by having a tree-like experience, absent defeaters, one would thereby possess a justification for "Here is a tree". That is, thanks to those hinges, one would be entitled to take one's perceptual experience at face value as favoring "Here is a tree" (as opposed to its skeptical counterpart, e.g. "I am a BIV hallucinating seeing a tree"). Thus, thanks to hinges, our perceptual experiences provide us with decisive, albeit fallible and defeasible, reasons in favor of the corresponding ordinary empirical propositions.

Furthermore, on this picture one can actually offer one's perceptions as reasons in support of one's claim that, say, there is a tree where one is looking at. For, given one's available evidence and the suitable hinges, absent defeaters, one can trust one's senses, and justifiably believe that there is a tree in virtue of one's current perceptions. Hence, I do not see why Pritchard thinks we should turn to disjunctivism to solve the Underdetermination-based skeptical paradox. Probably it is the quest for factive, indefeasible reasons that motivates him. Yet one would need arguments to follow Pritchard on that quest.

Let me close this section by considering the compatibility between Wittgenstein's views regarding (ordinary) knowledge and disjunctivism. There is a striking passage in On Certainty, in which he seems to be discussing ante litteram disjunctivism. It is worth quoting it in full:

"I know" has a primitive meaning similar to and related to "I see" ("wissen", "videre"). And "I knew he was in the room, but he wasn't in the room" is like "I saw him in the room, but he wasn't there". "I know" is supposed to express a relation, not between me and the sense of a proposition (like "I believe") but between me and a fact. So that the fact is taken into my consciousness. (Here is the reason why one wants to say that nothing that goes on in the outer world is really known, but only what happens in the domain of what are called sense-data.) This would give us a picture of knowing as the perception of an outer event through visual rays which project it as it is into the eye and the consciousness. Only then the question at once arises whether one can be certain of this projection. 
And this picture does indeed show how our imagination presents knowledge, but not what lies at the bottom of this presentation. (OC 90)

Wittgenstein was struck by the fact that in German the verb for "to know" is "wissen", which has the same root as the Latin "videre" that obviously means "to see". He also recognized the factivity of "to know". For instance, in OC 178, he writes

the wrong use made by Moore of the proposition "I know..." lies in his regarding it as an utterance as little subject to doubt as "I am in pain". And since from "I know it is so" there follows "It is so", then the latter can't be doubted either.

Taking knowledge to be akin to seeing, together with its factivity, produces a captivating "picture", as he calls it. Namely, a picture according to which knowledge would consist in taking outer facts into one's consciousness. Yet this is just a picture, and a bad one at that, for him. We do not take outer facts into consciousness; nor do we have knowledge only of inner facts, since the latter, being mental in nature, might be thought of being taken in consciousness directly. Rather, we only have perceptual experiences, testimonies, and reasoning procedures, which can lend support to our beliefs thanks to pertinent hinges. Our knowledge, as fallible as is, just consists in having true beliefs supported by defeasible reasons. Indeed, it is of the essence of knowledge, for Wittgenstein, that it be defeasible and this can be so only if knowledge does not depend on or entail having factive reasons for the propositions known. As he writes in OC 12,

'I know' seems to describe a state of affairs which guarantees what is known, guarantees it as a fact. One always forgets the expression 'I thought I knew'.

Disjunctivism, with its insistence on factive reasons, is forgetful of this grammatical fact, as Wittgenstein would consider it. For, saying that one does know that $p$, iff one has factive reasons for $p-$ viz. because one has taken in the very fact that $p$ - excludes the possibility of being wrong - that one's reasons may not be conclusive - and that $p$ isn't the case. Yet Wittgenstein insists that it is only when that possibility remains open that we do have, and are allowed to claim, knowledge. When that possibility is not open, then we are actually stumbling on something categorically different. Namely, a hinge. To put it otherwise, for Wittgenstein it is of the essence of knowledge that it be fallible. Since knowing that $p$ entails $p$, the only room for fallibility there is has to do with the kind of reasons one has for believing that $p$. If those, in turn, are 
factive, then no room is left for knowledge of $p$ to be fallible. Hence, by contraposition, reasons for knowledge of $p$ cannot be factive.

Thus, to sum up. I think Wittgenstein is more explicit than Pritchard about our attitude towards hinges and that he would have had stronger arguments than Pritchard's to hold that Closure is simply not applicable to entailments involving hinges: either because ultimately they are not propositions, or because their rule-like role would prevent them from being objects of belief and knowledge. Furthermore, I have maintained that there is enough in On Certainty to counter Underdetermination-based forms of skepticism without endorsing disjunctivism. Finally, I have claimed that disjunctivism would be at odds with Wittgenstein's own views about knowledge.

\section{A more Wittgensteinian hinge epistemology}

Let me close by presenting a different hinge epistemology - something Wittgenstein wasn't interested in developing and would have considered a misguided project - but which $I$ think would be of interest to contemporary practitioners of the discipline. Moreover, let me suggest how such a version of hinge epistemology would remain more faithful than its previously examined kin to the core ideas presented in $O n$ Certainty.

First, contrary to Wittgenstein's own pronouncements, it had better divorce epistemic considerations from semantic ones and focus on the former rather than the latter. For considering skeptical doubts meaningless would require endorsing a view of linguistic meaning that is very remote from mainstream philosophy nowadays and for good reasons. By so doing, it would immediately foreclose on a therapeutic response to skepticism of the kind propounded by Conant (1998), and more recently by Penelope Maddy (2017), but it would also foreclose on those developments of Wittgenstein's views which capitalize on the idea that skeptical doubts are nonsensical, or illusory, like Schönbaumsfeld's (2017). Second, it should explicitly embrace the idea that hinges are propositions, which are at least minimally truth-apt. ${ }^{11}$ That is to say, they have semantic content, which can be meaningfully negated, or embedded in conditional statements or become the object of a propositional attitude of acceptance. Third, it should insist on the idea that justification and knowledge do not take place in the void. Rather, they always depend on there being certain hinges, which, as such, cannot themselves be justified (evidentially or non-evidentially), or known, yet allow us to acquire evidence and justification for or against ordinary empirical propositions. Finally, I think it should take a firm stance on the kind of propositions that can play such a hinge-role. In my view, at least

${ }^{11}$ For further considerations regarding the kind of truth enjoyed by hinges, see Coliva 2015, chapter 4 and Coliva 2018. 
when dealing with skepticism, ${ }^{12}$ hinges should be confined to general propositions, like "There is an external world" or "My sense organs are generally reliable", or even "I am not the victim of sustained and lucid dreams", which are necessary in order for us legitimately to take perceptual experiences to bear onto beliefs about mid-size physical objects. These propositions, that is, allow us to transcend our "cognitive locality". ${ }^{13}$ In this case, by allowing us to take mind-dependent evidence to bear onto beliefs about mind-independent objects.

It is worth pointing out that, on such a view, certain epistemic principles would fail. For instance, there wouldn't be transmission of justification from a set of evidentially justified premises for a given argument to its conclusion, even if the latter were entailed by them, when hinges figure as conclusions. Consider the following argument:

\section{MOORE}

(I) Here is a hand

(II) If there is a hand here, there is an external world There is an external world

If (III) has to be presupposed in order to have perceptual justification for (I), it can't itself be justified by an argument such as MOORE. Yet the transmission of justification wouldn't fail because a justification for (III) would be needed already in order to have justification for (I). Rather, it would fail simply because we cannot acquire justification to believe the conclusion of an argument, which - as unjustified and unjustifiable as it is - has to be taken for granted in order for its premises to be justified in the first place. Hence, as I have argued elsewhere, ${ }^{14}$ we would have a subtly different kind of transmission failure from the one originally advertised in Wright's (1985) writings on the topic.

Moreover, we would have failure of Closure for epistemic operators such as justification and knowledge. For even if we do possess justification or even knowledge for propositions like (I), we would have none for (III), which is entailed by them and that we do know it is entailed by them. I think this result is acceptable, for reasons that I have explored in more detail elsewhere. ${ }^{15}$ To put it briefly, because Closure would hold for

\footnotetext{
12 It remains an open issue what kind of hinges would be needed to acquire testimonial justification, for instance; or if there could be more local ones specific to particular kinds of inquiry.

13 I am borrowing Wright's (2004) expression here.

${ }^{14}$ Coliva 2012a, 2014, 2015.

${ }^{15}$ Cf. Coliva 2012a.
} 
arguments containing known entailments in which the conclusion is not a general proposition of the kind I would allow to play a hinge-role. Such arguments are the ones we are usually interested in in our everyday epistemic inquiries, when general presuppositions like "There is an external world" are taken for granted. Furthermore, Closure would fail in a limited amount of cases - i.e. when such hinges figure as the entailed conclusions - for principled reasons. That is to say, because of a conception of the structure of perceptual justification, which is independently plausible. ${ }^{16}$ Such a conception could in fact represent a desirable midway position in between so-called "liberal" and "conservative" accounts of perceptual justification, such as the ones respectively put forward by Pryor (2004) and Wright (1985, 2004), that impose too lax and too stringent requirements upon empirical justification, respectively. I have dubbed such a view the "moderate" conception of the architecture of perceptual justification. Central to it is the idea that perceptual justification is possible only thanks to taking for granted the relevant hinges, absent defeaters, while having the relevant course of experience.

Furthermore, we would get an answer to at least some form of skepticism, of Humean descent, along the following lines. ${ }^{17}$ Regarding ordinary empirical propositions, we can have justification and even knowledge of them, whenever we have an appropriate course of experience, absent defeaters, thanks to the relevant hinges, even if the latter are not justified or known. True, hinges themselves are beyond epistemic appraisal, but, actually, we are mandated by epistemic rationality itself to hold on to them. For they are constitutive of the practice of gathering evidence for or against ordinary empirical propositions on the basis of certain assumptions, which is itself constitutive of epistemic rationality. On a Wittgenstein-inspired epistemology, notions such as the one of epistemic rationality do not hang in the air. Rather, they depend on human practice and, in particular, on the practice of forming, assessing and withdrawing from beliefs about physical objects based on one's perceptual evidence. Hence, either a skeptic is a skeptic about epistemic rationality itself, or else, if he is merely a skeptic about a class of targeted propositions, like hinges, he will not be allowed to conclude that they fall beyond epistemic rationality. For, though unwarrantable, they are part of epistemic rationality as they are its constitutive elements. To exclude them from epistemic rationality would then be a categorial mistake just like the mistake of excluding rules from a game simply because they are not moves within the game. The correct notion of epistemic rationality could then be defined thus:

\footnotetext{
${ }^{16}$ I have presented it in Coliva 2012b, 2014 and have defended it in more detail in Coliva 2015.

17 As to Cartesian skepticism, by denying Closure, we would block the consequence that since we do not know that we are not BIVs we do not know there is a hand here. Moreover, if "I am not a BIV" were a hinge, then it too would turn out to be mandated by the lights of epistemic rationality.
} 


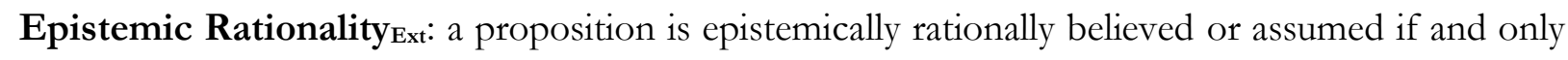
if either there is a (evidential) justification for it, or, while being unjustifiable, its assumption makes the acquisition of epistemic justifications possible.

The skeptical mistake would thus reside in holding on to too narrow a notion of epistemic rationality, which confines it to evidentially warranted propositions only. Moreover, it would depend on a misconception of the structure of justifications and knowledge, which requires them to spring only from more basic, yet similarly justified or even known propositions. This view can be defined as follows:

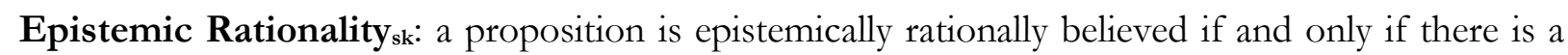
(evidential) justification for it.

Finally, the animal element in this Wittgenstein-inspired response would also be preserved, to some extent, in that it is acknowledged that hinges are what they are in virtue of a human practice that has not developed out of ratiocination. However, it is the normative element, which on my reading of Wittgenstein is the core aspect of $O n$ Certainty, that is given centre-stage insofar as certain unwarrantable propositions are allowed to play a constitutive role with respect to evidential justification and knowledge and, therefore, with respect to epistemic rationality itself. ${ }^{18}$

\section{References}

Coliva, A. 2010a Moore and Wittgenstein: Scepticism,Certainty and Common Sense, Palgrave, Macmillan.

Coliva, A. 2012a 'Varieties of failure (of warrant transmission-what else?!), Synthese 189/2, pp. 235-254.

Coliva, A. 2012b 'Liberals and conservatives. Is there a (Wittgensteinian) third way?', in A. Coliva (ed.) Mind, Meaning and Knowledge. Themes from the Philosophy of Crispin Wright, OUP, pp. 323-351.

Coliva, A. 2014 'Moderatism, transmission-failures, closure and Humean scepticism', in D. Dodd and E. Zardini (eds.) Scepticism and Perceptual Justification, OUP, pp. 248-272.

Coliva, A. 2015 Extended Rationality. A Hinge Epistemology, London, Palgrave Macmillan.

Coliva, A. 2016 "Review of Duncan Pritchard Epistemic Angst. Radical Skepticism and the Groundlessness of Our Believing”, Notre Dame Philosophical Reviews. URL: https://ndpr.nd.edu/news/epistemic-angst-radical-skepticism-and-the-groundlessness-of-ourbelieving/

Coliva, A. 2018 "What anti-realism about hinges could possibly be”, in C. Kyriacou and R. McKenna (eds.) Metaepistemology. Realism and Anti-Realism, London, Palgrave Macmillan, pp. 267-288.

${ }^{18}$ I have presented such an extended conception of epistemic rationality in Coliva 2012b, 2014 and further developed it in Coliva 2015. 
Coliva, A. 2019a "Against neo-Wittgensteinian entitlements", in P. Graham and N. Pedersend (eds.) New Essays on Entitlements, Oxford, Oxford University Press, forthcoming.

Coliva, A. 2019b "Strange bedfellows. On Pritchard's disjunctivist hinge epistemology", Synthese, forthcoming.

Conant, J. 1998 'Wittgenstein on meaning and use', Philosophical Investigations 21, pp. 222-50.

Kienzler, W. 2006 'Wittgenstein and John Henry Newman on certainty’, Grazer Philosophische Studien 71, pp. 117-138.

Kusch, M. 2016 “Wittgenstein on mathematics and certainty”, in A. Coliva \& D. Moyal-Sharrock (eds.) Hinge Epistemology, Leiden, Brill, pp. 48-71.

Maddy, P. 2017 What Do Philosophers Do? Skepticism and the Practice of Philosophy, Oxford, Oxford University Press.

McGinn, M. 1989 Sense and Certainty: A Dissolution of Scepticism, Oxford, Blackwell.

Morawetz, T. 1978 Wittgenstein and Knowledge. The Importance of On Certainty, Atlantic Highlands N. J., Humanities Press.

Moyal-Sharrock, D. 2005 Understanding Wittgenstein's On Certainty, London, Palgrave Macmillan.

Pritchard, D. 2016 Epistemic Angst. Radical Skepticism and the Groundlessness of Our Believing, Princeton, Princeton University Press.

Pritchard, D. 2019 'Wittgenstein on faith and reason: the influence of Newman', in M. Szatkowski (ed.) God, Truth and Other Enigmas, Berlin, De Gruyter, forthcoming.

Pryor, J. 2004 “What's wrong with Moore's argument?”, Philosophical Studies 14, pp. 349-378.

Schönbaumsfeld, G. 2017 The Illusion of Doubt, Oxford, Oxford University Press.

Stroll, A. 1994 Moore and Wittgenstein on Certainty, Oxford, Oxford University Press.

Williams, M. 2004 'Wittgenstein, truth and certainty', in M. Kölbel \& B. Weiss (eds.) Wittgenstein's Lasting Significance, Routlede, pp. 249-84.

Wittgenstein, L. 1969 On Certainty, Blackwell.

Wright, C. 1985 'Facts and certainty', Proceedings of the British Academy 71, pp. 429-472.

Wright, C. 2004 'Warrant for nothing (and foundations for free?), Aristotelian Society Supplementary Vol. 78/1, pp. 167-212.

Wright, C. 2014 'On epistemic entitlement (II). Welfare state epistemology', in D. Dodd and E. Zardini (eds.) Scepticism and Perceptual Justification, OUP, pp. 213-247. 